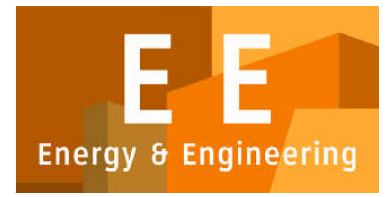

PAPER - OPEN ACCESS

\title{
Algoritma Artificial Bee Colony untuk Masalah Multi Depot Vehicle Routing Problem
}

\author{
Author $\quad:$ Andriansyah, dkk \\ DOI $\quad: 10.32734 /$ ee.v2i4.673 \\ Electronic ISSN $\quad: 2654-704 \mathrm{X}$ \\ Print ISSN : :2654-704X
}

Volume 2 Issue 4 - 2019 TALENTA Conference Series: Energy \& Engineering (EE)

This work is licensed under a Creative Commons Attribution-NoDerivatives 4.0 International License.

Published under licence by TALENTA Publisher, Universitas Sumatera Utara 


\title{
jiditi talentaliọi TALENTA Conference Series
}

Available online at https://talentaconfseries.usu.ac.id

\section{Algoritma Artificial Bee Colony untuk Multi Depot Vehicle Routing Problem}

(Algoritma Artificial Bee Colony untuk Multi Depot Vehicle Routing Problem)

\author{
Andriansyah $^{\mathrm{a}, \mathrm{b}}$, Hamka Ash Shiddieqy ${ }^{\mathrm{b} *}$, Prima Denny Sentia ${ }^{\mathrm{b}}$ \\ ${ }^{a}$ Laboratorium Komputasi \& Optimasi Industri, Program Studi Teknik Industi, Universitas Syiah Kuala, Banda Aceh 23111, Indonesia \\ ${ }^{b}$ Program Studi Teknik Industi, Universitas Syiah Kuala, Banda Aceh 23111, Indonesia
}

andriansyah@unsyiah.ac.id, hamkaash@gmail.com, primadennysentia@unsyiah.ac.id

\begin{abstract}
Abstrak
Perencanaan logistik untuk tanggap bencana merupakan hal yang sangat penting dilakukan agar menjamin kebutuhan para korban bencana. Penelitian ini mengkaji salah satu permasalahan logistik pasca bencana yaitu Vehicle Routing Problem (VRP) dengan fungsi tujuan meminimumkan waktu pengiriman kebutuhan korban. Berdasarkan survey yang telah dilakukan, VRP yang dikaji dalam penelitian ini adalah Multi Depot Vehicle Routing Problem (MDVRP). Algoritma Artificial Bee Colony (ABC) digunakan untuk pemecahan permasalahan. Algoritma $\mathrm{ABC}$ merupakan salah satu metode metaheuristik dimana pencarian solusi berdasarkan prilaku lebah. Hasil yang diperoleh menggunakan algoritma $\mathrm{ABC}$ adalah 6 kendaraan yang ditugaskan dari 3 gudang dimana setiap gudang menggunakan 2 kendaraan dengan total waktu tempuh 222 menit.
\end{abstract}

Kata Kunci: Bencana; Logistik; MDVRP; ABC

\begin{abstract}
Logistics planning for disaster response is very important to do to ensure the needs of disaster victims. This study examines one of the post-disaster logistical problems namely Vehicle Routing Problem (VRP) with the objective function of minimizing the delivery time of victims' needs. Based on the survey that has been conducted, the VRP studied in this study is the Multi Depot Vehicle Routing Problem (MDVRP). Artificial Bee Colony $(A B C)$ algorithm is used for solving this problem. This algorithm is one of the metaheuristic methods where the search for solutions is based on the principle of bees. The results obtained using the ABC algorithm are 6 vehicles assigned from 3 warehouse where each warehouse uses 2 vehicles with a total travel time of 222 minutes.
\end{abstract}

Keywords: Disaster; Logistic; MDVRP; ABC

\section{Pendahuluan}

Indonesia merupakan negara maritim terbesar di dunia, hal ini membuat Indonesia sangat kaya akan hasil laut. Indonesia juga diperkuat dengan letak geografis dan astronomi Indonesia yang sangat strategis yaitu berada diantara Samudra Hindia dan Samudra Pasifik serta terletak diantara Benua Australia dan Benua Asia. Meskipun demikian Indonesia sangat rentan terhadap bencana alam seperti gempa bumi dan gunung berapi, salah satu daerah Indonesia yang pernah diguncang gempa dengan kekuatan yang besar adalah Aceh yang terjadi pada tahun 2004 sehingga terjadi bencana Tsunami. Tsunami Aceh merupakan bencana alam terburuk dalam sejarah Indonesia karena banyak korban jiwa yang meninggal mencapai lebih dari 100 ribu jiwa [1]. Bencana alam merupakan bencana yang tidak dapat diprediksi kapan, dimana, dan siapa yang menjadi korbannya. Penanggulangan bencana merupakan cara mencegah lebih banyak korban yang meninggal, baik pada saat prabencana, saat bencana terjadi, dan pascabencana. Oleh karena itu waktu menjadi hal yang sangat kritis dalam penanggulangan bencana karena setiap menit banyak nyawa korban

(C) 2019 The Authors. Published by TALENTA Publisher Universitas Sumatera Utara

Selection and peer-review under responsibility of Seminar Nasional Institut Supply Chain dan Logistik Indonesia

(ISLI) 2019

p-ISSN: 2654-7031, e-ISSN: 2654-704X, DOI: 10.32734/ee.v2i4.673 
bencana yang dapat diselamatkan. Perencanaan logistik pasca bencana seharusnya sudah dilaksanakan jauh hari sebelum bencana tersebut terjadi, mulai dari barang logistik bencana, gudang logistik bencana, kendaraan logistik bencana, dan lokasi pengungsian. Saat bencana telah berakhir kebutuhan penting yang harus dipenuhi air, makanan, obat, pakaian, dan tempat perlindungan harus segera dikirim ke titik-titik yang menjadi area yang terdampak bencana tersebut sesuai dengan kebutuhan pengungsi [2].

Bencana selalu membuat ketidakpastian pada barang kebutuhan bencana yang sering kali tidak seimbangnya antara kebutuhan korban bencana dengan sumberdaya yang dimiliki. Proses perencanaan, mengelola, dan mengontrol sumberdaya yang tersedia untuk menanggulangi kebutuhan korban bencana disebut dengan logistik kemanusiaan [2]. Salah satu indikator dari logistik bencana yang menjadi faktor sukses atau tidaknya penanggulangan bencana tersebut adalah dari sistem logistik bencana [3]. Pengelolaan sistem logistik bencana atau yang biasa disebut dengan Disaster Relief Operation (DRO) mirip mulai dari konsep, teori, peralatan, dan prisip dengan Supply chain Management (SCM) untuk keperluan bisnis. Perbedaan antara DRO dan SCM, yaitu DRO berfokus untuk pemenuhan barang kebutuhan pengungsi dengan cepat dan tepat dengan tujuan mengurangi korban jiwa. Sedangkan SCM bertujuan untuk persaingan bisnis antar perusahaan dengan tujuan mengurangi harga produk dari biaya transportasi [4]. Pada DRO dibutuhkan ketersediaan barang yang cukup juga tidak efektif apabila pengiriman barang terhambat karena waktu merupakan hal yang sangat krusial dalam penanganan bencana [5].

Menurut [6] pada kejadian bencana sebelumnya yang pernah terjadi transportasi tidak masuk kedalam hal yang perlu dipertimbangkan untuk mengambil suatu keputusan. Beberapa kejadian tersebut membuat penumpukan pada pengangkutan barang kebutuhan bencana sehingga membuat kekacauan dalam sistem logistik bencana yang telah dibuat dengan matang dan menyebabkan keterlambatan bantuan logistik di lokasi bencana. Dalam transportasi logistik umum dikenal dengan istilah Vehicle Routing Problem (VRP). VRP klasik diperkenalkan pertama kali oleh Dantzig dan Ramser yang digunakan untuk mengoptimalkan jalur distribusi barang dengan jenis kendaraan yang sama mulai dari gudang menuju beberapa pelanggan [7]. Pada kenyataannya ada banyak jenis VRP yang dapat diklasifikasikan tergantung dengan kendala yang terjadi dan kebijakan perusahaan. Salah satu jenis VRP yang paling mirip dengan keadaan sesungguhnya di beberapa perusahaan adalah jumlah depot atau gudang yang lebih atau sama dengan dua, jenis VRP ini disebut dengan Multi Depot Vehicle Routing Problem (MDVRP) [8].

Pemecahan masalah VRP dapat dilakukan dengan metode analitik maupun metaheuristik. Namun pemecahan menggunakan metode analitik sangat tidak efisien karna lebih banyak mengeluarkan biaya dan waktu. Oleh karena itu metode secara metaheuristik sangat cocok digunakan karena hubungan antara kompleksitas yang ada di kasus dan waktu pemecahan masalah dapat digambarkan secara eksponensial [3]. Dalam penelitian ini akan menggunakan sebuah metode metaheuristik yaitu algoritma Artificial Bee Colony (ABC). Algoritma Artificial Bee Colony adalah sebuah penyelesaian masalah yang terinspirasi dari kebiasaan cara lebah dalam mencari makan di alam untuk mendapatkan solusi yang optimal [9]. ABC digunakan karena sifatnya lebah yang selalu mencari jalan yang terbaik dalam mencari makanan atau nektar pada bunga [10].

Beberapa penelitian sebelumnya yang menggunakan $\mathrm{ABC}$ dengan membandingkan solusi terbaik yang telah didapatkan dengan 12 kasus CVRP (Capacited Vehicle Routing Problem) dan didapatkan hasil bahwa terdapat perbedaan sebesar $4 \%$ lebih optimal dari ABC. Metaheuristik tidak dapat menjamin mendapatkan solusi yang global optimal, akan tetapi pasti solusi yang didapat menggunakan metaheuristik mendekati global optimal [10]-[11]. Pada penelitian lainnya $\mathrm{ABC}$ sangat efektif digunakan untuk menyelesaikan masalah optimasi yang rumit karena solusi yang didapatkan dalam kasus penentuan rute kendaraan lebih optimal dengan hasil jarak kendaraan yang lebih pendek dan error yang sangat kecil dibandingkan dengan metode lainnya [12].

Banda Aceh merupakan daerah yang terdampak bencana gempa dan Tsunami pada tahun 2004. Menurut data BPS Setidaknya 33\% warga Banda Aceh menjadi korban gempa dan Tsunami. Pada penelitian ini terdapat 3 gudang logistik bencana dan 12 titik kumpul pengungsi yang telah ditetapkan oleh pemerintah daerah Banda Aceh. Dalam proses distribusi barang logistik bencana diasumsikan kendaraan yang digunakan tidak terbatas dan jenis kendaraan yang digunakan sama. Penelitian ini dilakukan untuk mendapatkan rute menuju titik kumpul pengungsi dengan waktu tercepat. 


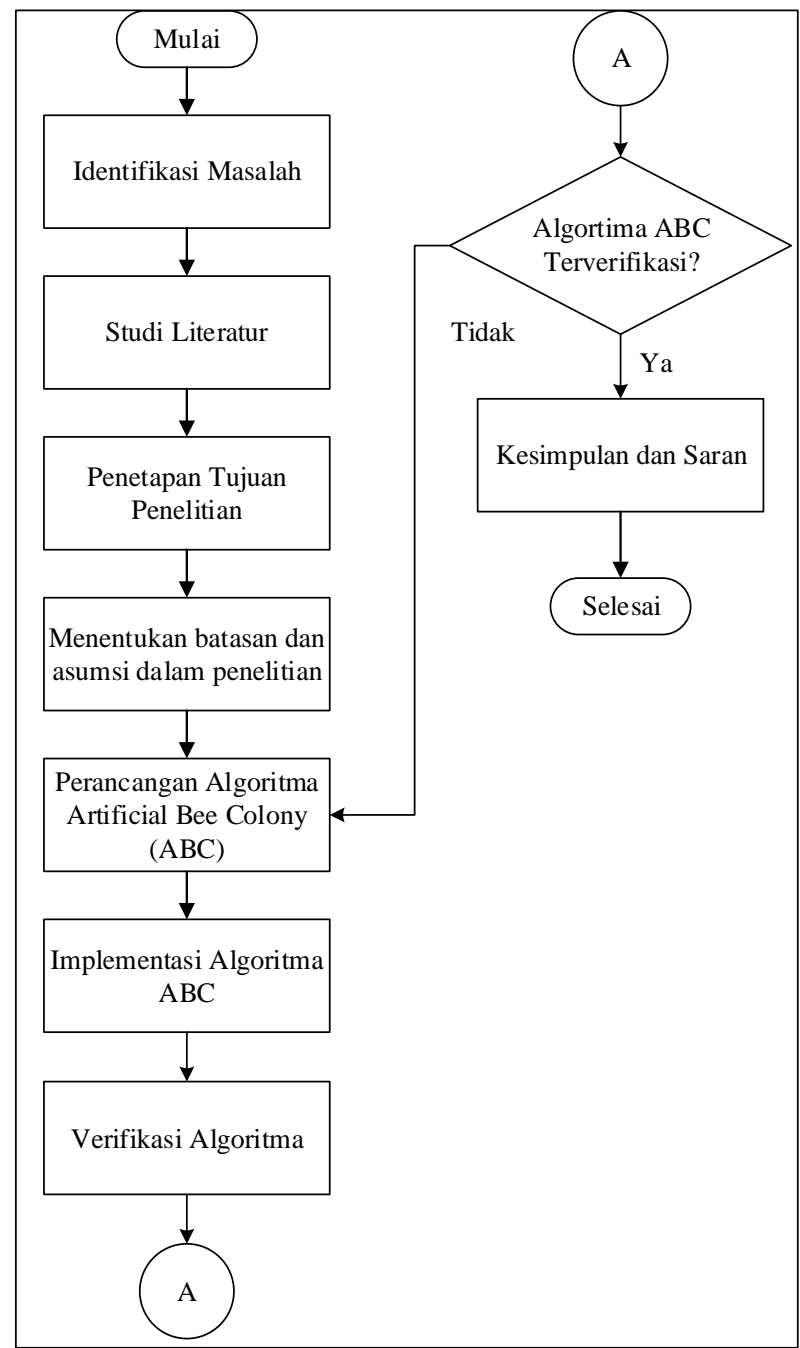

Gambar 1 Diagram Alir Penelitian

\section{Metodologi Penelitian}

Identifikasi masalah dilakukan dengan memahami permasalahan yang terdapat pada perencanaan pengiriman logistik bencana di Banda Aceh. Kemudian dilakukan studi literatur berdasarkan masalah yang terdapat pada pengiriman logistik bencana di Banda Aceh yaitu dengan kasus VRP dengan jenis MDVRP dan metode yang digunakan adalah metaheuristik dengan algoritma $\mathrm{ABC}$ untuk mendapatkan solusi dari masalah dari studi kasus. Setelah masalah teridentifikasi dan studi literatur didapatkan maka dapat ditetapkan tujuan dari penelitian ini.

Algoritma ABC akan dirancang menggunakan bahasa pemrograman MATLAB R2015a. Setelah algortima ABC selesai dirancang akan dilakukan verifikasi algorritma ABC untuk melihat apakah ada batasan penelitian yang terlanggar jika ada maka algoritma akan diperbaiki, jika tidak dilanjukan ke implementasi algoritma. Dalam proses pencarian solusi pada algrotma, akan dilajalankan pada komputer dengan spesifikasi : AMD E-350 Prosessor (2CPUs), $1.6 \mathrm{GHz}, 2 \mathrm{~GB}$ RAM dan system type 32 bit. Analitsis dilakukan dengan melihat beberapa kali pencarian solusi dengan menggunakan algoritma $\mathrm{ABC}$ sampai hasil dengan solusi terbaik diperoleh.

\section{Hasil Dan Pembahasan}

Berikut merupakan batasan yang digunakan dalam penelitian ini:

1. Setiap kendaraan harus berangkat dari depot dan tidak semua kendaraan harus digunakan.

2. Kendaraan yang sudah digunakan oleh sebuah depot tidak boleh digunakan oleh depot lainnya. 
3. Kendaraan yang sudah selesai mengantarkan barang kepada konsumen harus kembali kedepot yang sama pada saat berangkat.

4. Setiap konsumen akan dilayani tepat satu kali oleh sebuah kendaraan dan oleh satu depot.

5. Tidak ada konsumen yang tidak dilayani.

6. Jumlah permintaan dari seluruh konsumen dalam sebuah rute yang akan dilalui oleh sebuah kendaraan tidak boleh melebihi kapasitas kendaraan tersebut.

7. Jika suatu kendaraan mengunjungi suatu konsumen, maka kendaraan tersebut harus meninggalkan konsumen tersebut untuk menuju konsumen lainnya.

Berikut ini merupakan tahapan algoritma $\mathrm{ABC}$ yang digunakan dalam menyelesaikan MDVRP.

Langkah 0. Inisiasi parameter yang digunakan dalam algoritma $\mathrm{ABC}$, yaitu colony size, iterasi maksimum, sequence, dan limit maksimum.

Langkah 1. Fase inisial, untuk tiap lebah, solusi awal didapatkan secara random, kemudian hitung fitness atau kapasitas dan waktu solusi awal dari setiap lebah.

Langkah 2. Iterasi $=1$.

Langkah 3. Fase Employed bee, untuk tiap employed bee, perbaharui employed bee menggunakan neighborhood operator, yaitu swap operator dan swap sequence. Hitung fitness tiap employed bee seperti fase initial. Jika solusi dari employed bee lebih baik dari solusi sebelumnya maka update solusi lama dengan solusi dari employed bee, jika tidak tambahkan nilai limit dengan 1.

Langkah 4. Hitung probabilitas tiap employed bee.

Langkah 5. Fase Onlooker bee, untuk setiap onlooker bee, pilih solusi dari employed bee dengan menggunakan teknik roulette wheel selection. Tentukan solusi baru employed bee dengan menggunakan neighborhood operator yaitu insert operator dan insert sequence. Hitung fitness setiap onlooker bee.

Langkah 6. Fase Scout bee. Hitung jumlah limit tiap lebah. Jika limit > limit maksimum, tinggalkan solusi yang tidak mengalami peningkatan, jika limit < limit maksimum, scout bee memilih solusi sebelumnya.

Langkah 7. Simpan solusi terbaik yang dicapai saat ini

Langkah 8. Iterasi $=$ Iterasi +1

Langkah 9. Jika Iterasi = iterasi maksimum maka algoritma berhenti.

Tabel 1 merupakan parameter yang digunakan dalam algortima ABC.

Tabel 1. Parameter ABC

\begin{tabular}{cc}
\hline Parameter ABC & Nilai \\
\hline Colony Size & 150 \\
Iterasi maksimum & 2 \\
Sequence & 100 \\
Limit maksimum & 350 \\
\hline
\end{tabular}

\subsection{Fase Employed Bee}

Pada fase employed bee pencarian solusi baru dilakukan dengan swap operator. Swap operator digunakan untuk menentukan 2 indeks dari solusi awal untuk ditukar dimana indeks $1 \neq$ indeks 2 . Ilustrasi swap operator dapat dilihat pada gambar 2. 


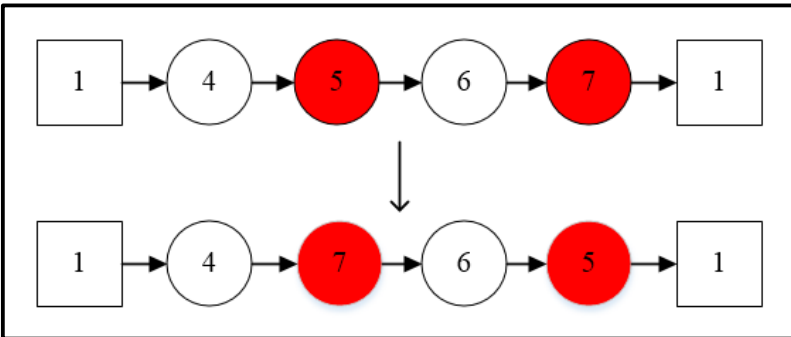

Gambar 2. Swap Operator

Sedangkan swap sequence merupakan kumpulan dari swap operator. jika solusi yang didapatkan dari swap operator lebih baik dari solusi awal maka solusi diupdate dan solusi dari swap operator digunakan kembali untuk swap operator selanjutnya, jika solusi dari swap operator lebih buruk dari solusi awal maka nilai trial ditambah 1 dan gunakan solusi awal kembali untuk employed bee sampai jumlah sequence habis.

$$
\begin{aligned}
\mathrm{Beei} & =\mathrm{Bee}_{i}+\mathrm{SS} \\
& =\mathrm{Bee}_{i}+\left(\mathrm{SO}_{1}, \mathrm{SO}_{2}, \mathrm{SO}_{3} \ldots, \mathrm{SO}_{n}\right) \\
& \left.\left.\left.=\left(\mathrm{Bee}_{i}+\mathrm{SO}_{1}\right)+\mathrm{SO}_{2}\right)+\mathrm{SO}_{3}\right) \ldots+\mathrm{SO}_{n}\right)
\end{aligned}
$$

Keterangan :

$$
\begin{array}{ll}
S S & =\text { Swap Sequence } \\
S O_{n} & =\text { Swap Operator ke-n } \\
n & =\text { Banyak Swap Sequence }
\end{array}
$$

\subsection{Hitung Probabilitas Tiap Employed Bee}

Setelah sequence pada employed bee berhenti maka dilakukan perhitungan probablilitas untuk tiap employed bee menggunakan persamaan berikut :

$$
P_{i j}=\frac{F\left(\theta_{i}\right)}{\sum_{k=1}^{s} F\left(\theta_{k}\right)}
$$

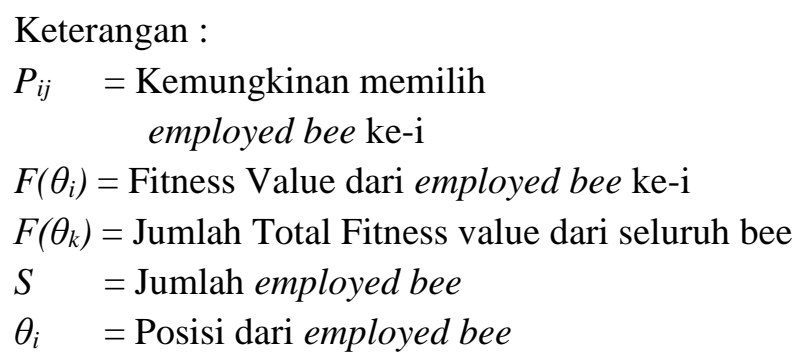

\subsection{Fase Onlooker Bee}

Pada fase onlooker bee pencarian solusi dilakukan dengan insert operator dengan 2 indeks ditentukan kemudian salah satu indeks tersebut disisipkan keurutan indeks lainnya. Ilustrasi insert operator dapa dilihat pada gambar 3. 


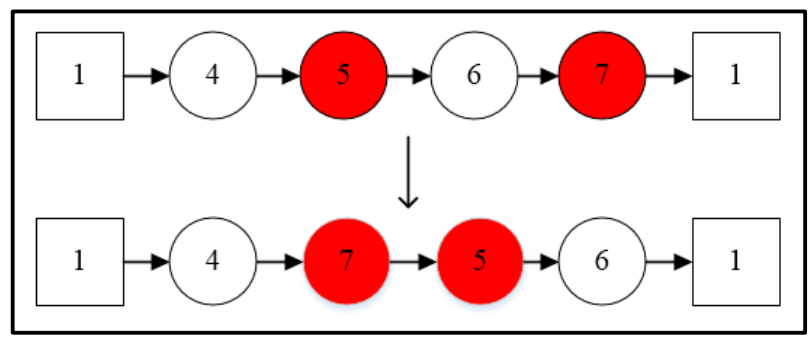

Gambar 3. Insert Operator

Sedangkan insert sequence merupakan kumpulan dari insert operator yang dimana langkah penentuan solusi terbaik sama seperti fase employed bee.

$$
\begin{aligned}
\mathrm{Beei} & =\mathrm{Bee}_{i}+I S \\
& =\mathrm{Bee}_{i}+\left(\mathrm{IO}_{1}, I \mathrm{I}_{2}, I \mathrm{IO}_{3} \ldots, I \mathrm{I}_{n}\right) \\
& \left.\left.\left.=\left(\mathrm{Bee}_{i}+I \mathrm{I}_{1}\right)+I \mathrm{O}_{2}\right)+I \mathrm{O}_{3}\right) \ldots+I \mathrm{O}_{n}\right)
\end{aligned}
$$

Keterangan :

$$
\begin{array}{ll}
I S & =\text { Insert Sequence } \\
I O_{n} & =\text { Insert Operator } \text { ke-n } \\
n & =\text { Banyak Insert Sequence }
\end{array}
$$

\subsection{Fase Scout Bee}

Setelah melewati fase employed bee dan onlooker bee maka akan dihitung kualitas dari masing masing bee. Perhitungan kualitas yang akan dilihat adalah apabila jumlah nilai limit melebihi maxlimit maka solusi dari bee tersebut akan dihapus dan diganti dengan solusi baru dengan random dan mengubah nilai trial menjadi 0 .

Tabel 2. Solusi Beberapa Kali Percobaan

\begin{tabular}{lllll}
\hline Percobaan Ke - i & Gudang digunakan & Kendaraan digunakan & Waktu Total Perjalanan (menit) & Waktu Komputasi (detik) \\
\hline 1 & 3 & 6 & 225 & 41,33 \\
2 & 3 & 6 & 222 & 43,71 \\
3 & 3 & 6 & 224 & 41,63 \\
4 & 3 & 6 & 227 & 41,62 \\
5 & 3 & 6 & 222 & 44,76 \\
6 & 3 & 6 & 224 & 41,88 \\
7 & 3 & 6 & 224 & 41,35 \\
8 & 3 & 6 & 225 & 44,03 \\
9 & 3 & 6 & 224 & 44,80 \\
10 & 3 & 6 & 227 & 44,22 \\
\hline
\end{tabular}


Tabel 3. Solusi Rute Terbentuk

\begin{tabular}{lllll}
\hline $\begin{array}{c}\text { Gudang } \\
\text { digunakan }\end{array}$ & $\begin{array}{l}\text { Kendaraan } \\
\text { digunakan }\end{array}$ & Rute & $\begin{array}{c}\text { Kapasitas } \\
\text { (Kg) }\end{array}$ & $\begin{array}{c}\text { Waktu } \\
\text { Perjalanan } \\
\text { (Menit) }\end{array}$ \\
\hline Percobaan Ke-2 & 1 & $1-12-11-1$ & \\
\hline G1 & 2 & $1-14-13-1$ & 6271 & 13 \\
\hline G2 & 1 & $2-10-2$ & 7688 & 28 \\
\hline G3 & 2 & $2-4-2$ & 5782 & 36 \\
\hline Total & 1 & $3-9-8-7-6-15-3$ & 6331 & 52 \\
\hline Percobaan Ke-5 & 2 & $3-5-3$ & 6450 & 67 \\
\hline G1 & 1 & $1-14-13-1$ & 7619 & 26 \\
\hline G2 & 2 & $1-12-11-1$ & 40141 & 222 \\
\hline G3 & 1 & $2-10-2$ & 7688 & 28 \\
\hline Total & 2 & $2-4-2$ & 6271 & 13 \\
\hline & 2 & $3-15-6-7-8-9-3$ & 5782 & 36 \\
\hline
\end{tabular}

\subsection{Hasil Algoritma Artificial Bee Colony}

Deskripsi dalam kasus pengiriman barang logistik di Banda Aceh adalah terdapat 3 gudang yang tersebar di daerah Banda Aceh dan sekitarnya yang akan melayani 12 titik kumpul pengungsi. Proses distribusi dilakukan dengan truk yang diasumsikan jumlahnya tidak terbatas dan kapasitas untuk setiap kendaraan adalah sama. Pencarian solusi dalam penelitian ini berbeda setiap kali percobaan implementasi algoritma, oleh sebab itu perlu dilakukan beberapa kali percobaan untuk melihat solusi yang didapat apakah sudah optimal. Dari tabel 2 dapat dilihat dalam 10 kali percobaan waktu total perjalanan kendaraan terdapat 2 percobaan dengan hasil terendah yang nilainya sama yaitu pada percobaan ke-2 dan percobaan ke-5, yang membedakan dari kedua percobaan tersebut hanya urutan rute yang harus dilayani.

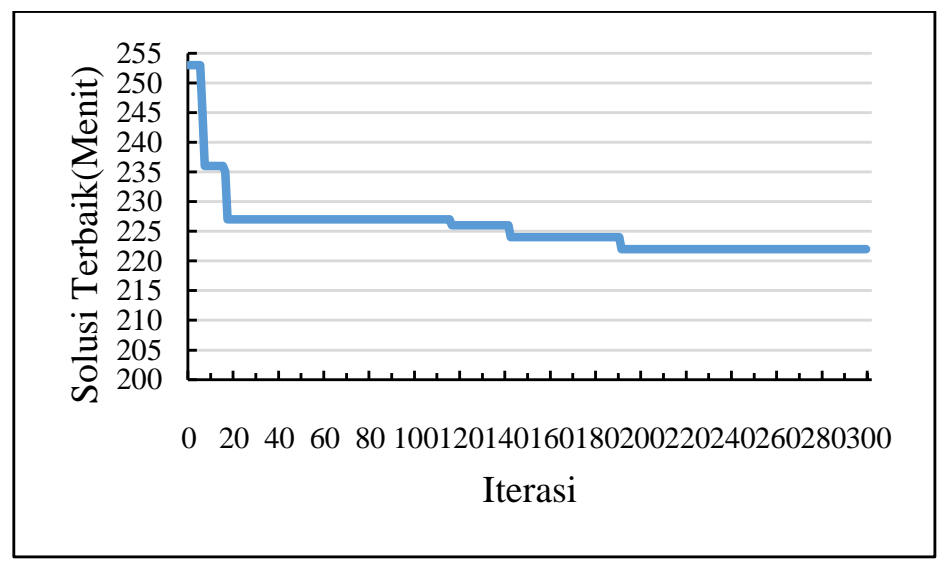

Gambar 4. Konvergensi Algoritma ABC 
Tabel 4.Verifikasi Algoritma

\begin{tabular}{|c|c|c|c|c|c|c|c|c|c|c|c|}
\hline \multirow{2}{*}{ Percobaan } & \multirow{2}{*}{ Gudang } & \multirow{2}{*}{ Kendaraan } & \multirow{2}{*}{ Rute } & \multirow{2}{*}{ Kapasitas (Kg) } & \multicolumn{7}{|c|}{ Batasan } \\
\hline & & & & & (1) & (2) & (3) & (4) & (5) & $(6)$ & (7) \\
\hline \multirow{6}{*}{2} & \multirow{2}{*}{ G1 } & 1 & $1-12-11-1$ & 6271 & $\mathrm{TM}$ & TM & $\mathrm{TM}$ & TM & TM & $\mathrm{TM}$ & $\mathrm{TM}$ \\
\hline & & 2 & $1-14-13-1$ & 7688 & TM & $\mathrm{TM}$ & $\mathrm{TM}$ & $\mathrm{TM}$ & $\mathrm{TM}$ & TM & TM \\
\hline & \multirow{2}{*}{ G2 } & 1 & $2-10-2$ & 5782 & TM & $\mathrm{TM}$ & $\mathrm{TM}$ & $\mathrm{TM}$ & $\mathrm{TM}$ & TM & TM \\
\hline & & 2 & $2-4-2$ & 6331 & TM & TM & TM & $\mathrm{TM}$ & TM & TM & TM \\
\hline & \multirow[t]{2}{*}{ G3 } & 1 & $3-9-8-7-6-15-3$ & 6450 & $\mathrm{TM}$ & $\mathrm{TM}$ & $\mathrm{TM}$ & $\mathrm{TM}$ & $\mathrm{TM}$ & TM & TM \\
\hline & & 2 & $3-5-3$ & 7619 & TM & $\mathrm{TM}$ & TM & $\mathrm{TM}$ & $\mathrm{TM}$ & TM & TM \\
\hline \multirow{6}{*}{5} & \multirow{2}{*}{ G1 } & 1 & $1-14-13-1$ & 7688 & TM & $\mathrm{TM}$ & $\mathrm{TM}$ & $\mathrm{TM}$ & $\mathrm{TM}$ & TM & TM \\
\hline & & 2 & $1-12-11-1$ & 6271 & TM & $\mathrm{TM}$ & $\mathrm{TM}$ & $\mathrm{TM}$ & $\mathrm{TM}$ & TM & TM \\
\hline & \multirow{2}{*}{ G2 } & 1 & $2-10-2$ & 5782 & TM & TM & $\mathrm{TM}$ & $\mathrm{TM}$ & TM & $\mathrm{TM}$ & TM \\
\hline & & 2 & $2-4-2$ & 6331 & TM & TM & $\mathrm{TM}$ & $\mathrm{TM}$ & $\mathrm{TM}$ & TM & TM \\
\hline & \multirow[t]{2}{*}{ G3 } & 1 & $3-15-6-7-8-9-3$ & 6450 & $\mathrm{TM}$ & $\mathrm{TM}$ & $\mathrm{TM}$ & TM & $\mathrm{TM}$ & TM & TM \\
\hline & & 2 & $3-5-3$ & 7619 & TM & TM & $\mathrm{TM}$ & $\mathrm{TM}$ & TM & TM & TM \\
\hline
\end{tabular}

Keterangan :

TM : Tidak Melanggar

M : Melanggar

Berdasarkan solusi terbaik yang didapat dalam penelitian ini pada gambar 4 dapat dilihat bahwa pencarian solusi terbaik terdapat pada iterasi bee ke 190 didapatkan solusi terbaik dengan total waktu perjalanan 222 menit.

\subsection{Verifikasi Batasan Penelitian}

Verifikasi Batasan penelitian dilakukan dengan melihat batasan dengan hasil algoritma ABC.Tujuan dilakukan verifikasi batasan penelitian ini adalah untuk melihat kelogisan dari solusi yang didapatkan jika diimplementasikan ke kasus. Diharapkan pada verifikasi ini tidak ada solusi yang melanggar batasan, jika ada maka algortima ABC harus dirancang ulang sampai tidak ada batasan yang terlanggar. Berdasarkan tabel 4 dapat diketahui bahwa solusi yang diperoleh dari algoritma $\mathrm{ABC}$ tidak ada yang melanggar Batasan.

\section{Kesimpulan}

Dalam menyelesaikan masalah VRP dengan kasus MDVRP menggunakan algoritma ABC solusi waktu terbaik yang didapatkan adalah 222 menit, dimana proses distribusi dilakukan dengan menggunakan 3 gudang dengan menggunakan 6 kendaraan dimana masing-masing gudang menggunakan 2 kendaraan. Dalam mendapatkan solusi terbaik terdapat dua percobaan yang hasilnya sama yaitu pada percobaan ke 2 dan percobaan ke 5, yang membedakan hasil percobaan ini hanya urutan dari rute kendaraan ini, hal ini karena data waktu pengiriman bersifat euclidien yang artinya adalah jarak dari A ke B sama dengan jarak dari B ke A sehingga hasil yang didapatkan akan sama. 


\section{Referensi}

[1] B. Sugestiyadi, "Rumah dan Sekolah Terbuka Korban Tsunami Aceh dan Sumatra Utara," Fak. Tek. Univ. Negeri Yogyakarta, pp. 4-11, 2005.

[2] J. Qin, Y. Ye, and B. R. Cheng, "The emergency vehicle routing problem with uncertain demand under sustainability environments," Sustain., vol. 9, no. 2, 2017.

[3] Andriansyah and P. D. Sentia, "Penentuan Rute Kendaraan Pada Sistem Distribusi Logistik Pasca Bencana (Studi Kasus),” J. Manaj. Ind. dan Logistik, vol. 2, no. 1, pp. 75-83, 2018.

[4] I. N. Pujawan, N. Kurniati, and N. A. Wessiani, "Supply chain management for Disaster Relief Operations: principles and case studies," Int. J. Logist. Syst. Manag., vol. 5, no. 6, p. 679, 2009.

[5] W. Yi and A. Kumar, "Ant colony optimization for disaster relief operations," Transp. Res. Part E Logist. Transp. Rev., vol. 43, no. 6, pp. 660-672, 2007.

[6] A. S. Thomas and L. R. Kopczak, "From logistics to supply chain management: the path forward in the humanitarian sector," Fritz Inst., pp. $1-15,2005$.

[7] Ç. Koç, O. Jabali, and G. Laporte, "Thirty years of heterogeneous vehicle routing,” Eur. J. Oper. Res., vol. 249, no. 1, pp. 1-21, 2016.

[8] T. Demirel and S. Yilmaz, "A New Solution Approach To Multi-Depot Vehicle Routing Problem With Ant Colony Optimization," J. MultiValuted Log. soft Comput., vol. 18, no. March 2016, pp. 421-439, 2012.

[9] D. T. Pham, A. Ghanbarzadeh, and E. Koc, "Bee Algorithm A Novel Approach to Function Optimisation," Manuf. Eng. Cent., no. September, 2005.

[10] M. Nikolic, D. Teodorovic, and M. Selmic, "Solving the vehicle routing problem with time windows by Bee Colony Optimization metaheuristic," Proc. 1st Logist. Int. Conf., no. November, pp. 44-48, 2013.

[11] I. Brajevic, "Artificial bee colony algorithm for the capacitated vehicle routing problem,” Proc. Eur. Comput. Conf., pp. 239-244, 2011.

[12] A. S. Bhagade and P. V Puranik, "Artificial Bee Colony ( ABC ) Algorithm for Vehicle Routing Optimization Problem," Int. J. Soft Comput. Eng., no. 2, pp. 329-333, 2012. 